Gender-diverse practitioners in early years education and care (EYEC): a cross-cultural study of Scotland, Hong Kong, and Mainland China

Yuwei Xu

Institute of Education, University College London, London, UK

yuwei.xu@ucl.ac.uk

World count: 7,054 


\section{Gender-diverse practitioners in early years education and care (EYEC): a cross-cultural study of Scotland, Hong Kong, and Mainland}

\section{China}

This paper discusses whether practitioners' gender subjectivities influence pedagogies and practices in early years education and care (EYEC) settings and whether an increase of men's participation can improve gender diversity in EYEC. It draws on poststructuralist theories, understanding gender as the product/outcome of the social formation of subjects and the process of subjectification. This is illustrated through accounts for how individual practitioners from Scotland, Hong Kong, and Mainland China discursively construct their gender subjectivities, in accordance with the respective cultural discourses that shape work with young children in EYEC in the three contexts. 34 practitioners from 17 EYEC settings (1 male and 1 female practitioner from each setting) in the cities of Edinburgh, Hong Kong, and Tianjin were interviewed. The study finds that participant practitioners' constructions of gender subjectivities vary within and across contexts, and gender-binary discourses are to various extent prevalent in all three contexts. This paper argues for a crosscultural approach to gender-sensitive teacher training, to interrogate popular discourses that advocate for men to fulfil complementary roles in EYEC to women and to challenge gender binary thinking that persists in EYEC and beyond.

Keywords: gender; early years education and care; diversity; cross-cultural; gender binary

\section{Introduction}

This paper discusses whether practitioners' gender subjectivities influence pedagogies and practices in early years education and care (EYEC) settings and whether an increase of men's participation can improve gender diversity in EYEC. It illustrates how individual practitioners from Scotland, Hong Kong, and Mainland China discursively construct their gender subjectivities in accordance with the respective cultural discourses that shape work with young children in EYEC in the three contexts. Gender 
subjectivity is used in this paper to describe findings on practitioners' views and reflections on gender, in alignment with Foucault's (1982) theory of the social formation of subjects and the process of subjectification. Human beings are socially made subjects in power relations (Foucault 1982) and subjectivity is thus the ways in which, consciously or unconsciously, one relates oneself to the social world (Blaise 2005). Practitioners' gender subjectivities indicate to what extent they conform, accept, resist, subvert, or challenge gender norms that shape EYEC and its wider society, in their daily practices and interactions with children. In this paper, a literature review on the gendered construction of EYEC as a 'feminised' profession is presented first. The paper then introduces arguments around men's contributions to EYEC, as shaped by a gender-binary thinking that underpins the 'feminisation' of the sector. After descriptions of methodologies, the paper presents findings from interviews with 34 practitioners on their perceived understandings of EYEC work, followed by discussions on how those practitioners' gender subjectivities confirm/challenge existing gender norms in their cultures. The paper concludes by suggesting a cross-cultural approach to gendersensitive teacher training, to interrogate popular discourses that advocate for men to fulfil complementary roles in EYEC to women and to challenge gender binary thinking that persists in EYEC and beyond.

\section{EYEC as a gendered workforce}

Statistics have shown that the EYEC workforce globally is gender-imbalanced, with women accounting for the majority of the staff population. The Education at a Glance 2018 report indicates that the average percentage of female practitioners in the preprimary (including EYEC) level of education was 97\% among all OECD countries in 2016 (OECD 2018). Four per cent of staff in the day care of children sector in Scotland were male in 2017 (Scottish Social Services Council 2018); available data shows that 
there were 2.1\% male kindergarten teachers (practitioners) in Hong Kong (HK) in 2017 (Census and Statistics Department 2018); and the percentage of male full-time practitioners working in pre-school education institutions in Mainland China was $2.21 \%$ in 2017 (Ministry of Education of the People's Republic of China [PRC] 2018). Although variations in international EYEC systems are significant, a common feature of the so-believed 'feminisation' of EYEC is noted (Laere et al. 2014) and may be related to a shared pattern of social and historical constructions.

EYEC is historically built upon care and education separately or jointly in its traditions (Laere et al. 2014; Peeters, Rohrmann, and Emilsen 2015). The 'caring' version of EYEC was originated from an extension of domestic mothering that is culturally considered to be women's job as derived from their 'naturality' (Laere et al. 2014). Because in traditional gender discourses essentialist female characteristics are regarded as less valuable than male gender characteristics, the 'caring' job done by women as a profession is also devalued (Peeters, Rohrmann, and Emilsen 2015). The low social status of the 'caring' profession is further enhanced by the classed issue that early child care services were provided mainly for working class children whose parents were at work, and that carers were traditionally recruited from women of the 'lower' classes (Osgood 2005; Laere et al. 2014). Usually accompanied by low pay scales and limited promotion spaces, EYEC as a 'caring' profession has long been socially and economically disadvantaged, a situation that persists in many European countries and in China (Laere et al. 2014; Peeters, Rohrmann, and Emilsen 2015; Yang and McNair 2019).

Meanwhile, the promotion of educational purposes in EYEC offers the profession the potential to be held in higher social esteem (Laere et al. 2014; Peeters, Rohrmann, and Emilsen 2015); neuroscience and economic science theories 
conceptualise the early years as 'the best preparation for academic achievements in later years as well as for a thriving labour market' (Peeters, Rohrmann, and Emilsen 2015, p.308). However, this way of promoting the EYEC workforce has been criticised for reflecting 'masculine' notions of education. There seems to be a hierarchy between education and care in EYEC, which is a combined consequence of mind-body dualism and gender binarism in many societies (Laere et al. 2014; Warin 2014; Peeters, Rohrmann, and Emilsen 2015). 'Caring' work is considered to be instrumentalised for educational activities, and children's physical, emotional and social needs are often sacrificed for the educational agenda that attends only to children's development of 'knowledge' (Laere et al. 2014; Warin 2014).

\section{Men in EYEC: what are their contributions?}

Underpinned by the dichotomous constructions of care and education, it is expected that increased male participation could lead to a higher social status for EYEC by adding 'masculine' (educational) values to the profession (Sumsion 2005; Ho and Lam 2014). It is also expected that men will fulfil roles that are complementary to those of women's, including: helping to establish a gender-balanced workforce, adding to the diversity of EYEC pedagogy (assuming that men and women may teach differently), and particularly, providing boys with male role models (Brownhill 2015; Rohrmann and Emilsen 2015; Warin 2019). There are assumptions that EYEC being a 'feminized' community is detrimental to boys' gender development and wellbeing, in a sense that there is a lack of male role models for boys (especially for those who lack a father

figure at home) to learn about being a 'man' (Tennhoff, Nentwich and Vogot 2015). For example, in China, male practitioners are desired to rescue the 'crisis' of boys, who are criticized for a lack of masculinity and for being increasingly feminised (Xu and Waniganayake 2018; Yang and McNair 2019). Such expectations, however, fall into the 
problem of hegemonic gender essentialisation and gender binary in expecting all men to be the same and to be different from their opposite gender (women) (Blaise 2005; Warin 2019).

The inappropriateness of referring to traditional gender discourses in attracting more men to EYEC is evident in the little progress of male participation in EYEC in many European countries, despite governmental endeavours to take initiatives to increase male numbers (Rohrmann and Emilsen 2015; Peeters, Rohrmann, and Emilsen 2015). Indeed, the gender stigma that devalues care in EYEC and the binary, essentialist views of gender as illustrated above are detrimental to both men and women working in EYEC (Warin 2014; Tennhoff et al. 2015); and men's participation is likely to reproduce gender stereotypes and inequalities and to perpetuate cultures of hegemonic masculinity in the workforce and beyond (Burn and Pratt-Adams 2015; Tennhoff et al. 2015; Xu and Waniganayake 2018; Warin 2019;).

Despite the persistent power of dominant gender discourses in many countries that constantly shape EYEC as a gender-unequal profession with or without men's involvement, challenges to the 'gender regime' of EYEC (Peeters, Rohrmann, and Emilsen 2015) are not impossible and men's participation in EYEC is still deemed to have the potential to "transform gender relations and subvert entrenched patriarchal gender regimes' (Warin 2014, p.93). The rising status of care in EYEC in countries such as Norway (Warin 2014) and the cultural shift towards positively valuing fathers' roles in their children's caring in Belgium, England, America and elsewhere (RobertsHolmes 2009; Laere et al. 2014; Livingston 2014) are such indications that suggest changes of social attitudes towards traditional gender structures, although some would argue that socio-economic factors will have significant impacts on the acceptance and practicality of increased fathering (Hauari and Hollingworth 2009; Johansson 2011). It 
is hoped that men's participation in EYEC could help boost those social changes for a gender-equitable and -inclusive EYEC and society, but not through embracing their 'hegemonic masculinity' as men. Instead, men together with women EYEC practitioners, are both expected to demonstrate to the children ways of being a man or a woman, or more appropriately being individuals, that can go beyond existing gender norms and structures, and to provide children with an equitable, diversified, inclusive, and respectful EYEC.

\section{Methods}

Building upon those arguments around whether the assumed 'feminisation' of EYEC impacts pedagogies and practices in the sector and whether men's participation in EYEC contributes to challenging dominant gender norms, this paper draws on findings from the author's PhD study (Xu 2018) to add cross-cultural insights into those debates. Three under-researched localities - Scotland, Hong Kong, and Mainland China - were selected to investigate the topic, adding new insights into how practitioners' gender subjectivities in EYEC are situated in the wider socio-cultural contexts. In Scotland, there is a recent political drive for men to work in childcare, so that gender stereotypes of men's capacity to care can be challenged; although the Hong Kong government claimed no plan for launching specific policies to support more men into EYEC (as it is believed to be against gender equality), there is an emerging public expectation that more men are needed in kindergartens to promote young children's physical health; whereas in China, there are particular concerns by the general public and media towards boys' 'feminisation' and male Chinese kindergarten teachers are expected to 'benefit' boys' development of masculinity. The study is one of the few that employs crosscultural and comparative approaches to research about gender and men's participation in EYEC, recognizing cultural influences in the shaping of a gendered EYEC workforce 
in different parts of the world (Brody 2014; Rohrmann and Brody 2015). Two research questions are addressed in this paper, including:

1. What is the relationship between male and female practitioners' gender subjectivities and their work with young children in EYEC?

2. To what extent do individual practitioners challenge dominant gender discourses and contribute to gender diversity in EYEC?

\section{Research design}

The study adopted a poststructuralist approach of interpretivism in qualitative research, highlighting the fluidity and multiplicity of interpretations from the researchers and the researched (O'Connor 2001). Those interpretations are situated in and shaped by discourses (venues where knowledge and power work to construct subjects' thoughts and behaviours) in the specific research contexts and at the particular times when this research was conducted. A multi-method approach was employed including observations on practitioner-child interactions; interviews about practitioners' perceptions of their working experiences; and pictorial activities exploring children's perceptions of practitioners' gender. This paper primarily reports on findings from interviews with practitioners.

\section{Sampling and participants}

17 EYEC settings were selected from the cities of Edinburgh, Hong Kong and Tianjin using snowball sampling. Although the cultures in the three researched contexts are argued to be nested in those settings/cities, findings from this research cannot be uncritically generalized to other institutions/regions within them (Tobin et al. 2009). Thirty-four practitioners participated in the interviews, with 1 male and 1 female practitioner who work in the same classroom from each setting. They were all full-time 
staff members that work with the children (aged 2-6) on a regular basis; the diversity in their qualifications, ages, positions, institutions, and working experiences is similar to that of each EYEC system (see Table 1 [Table 1 near here]). This study is not intended to claim any intersections of class, race and gender in shaping EYEC practitioners' subjectivities. Further research is needed taking intersectional approaches to explore equality and diversity in EYEC.

In this paper, early years practitioners, kindergarten teachers, nursery nurses and any other working titles that used in different settings, are all referred to as 'practitioners' unless specified. Any information that may lead to identifications of participants are avoided. Names of practitioners were replaced with pseudonyms.

\section{Data analysis}

Interview recordings with practitioners were transcribed by the author and were then analysed in their original languages (English, Cantonese and Mandarin). The author's familiarity with all three languages and his own previous experiences as an early years practitioner made it possible to reduce the cross-language impact on this research to a minimum (Twinn 1997). NVivo was used to assist with managing the large amount of data from practitioners' interviews. A hybrid approach of inductive and deductive coding and theme development was used to identify key themes (Braun and Clarke 2006; Fereday and Muir-Cochrane 2006). The codes were then analysed to identify major patterns within and across the three contexts, as well as to note down outstanding cases. Cross-cultural comparisons and analyses were conducted throughout, noting different or similar discourses that impact on the gender dynamics and complexities in EYEC settings in Scotland, Hong Kong and Mainland China. 


\section{Results}

In this section, selected findings from the original study are presented to address the two research questions set earlier in this paper. The findings are categorized into three themes, including: gender and roles of EYEC practitioners, male role models, and gendered practices and pedagogies. Where similarities are found between practitioners' subjectivities from Mainland China and Hong Kong, the words 'China/Chinese' are used to include both.

\section{Gender and roles of EYEC practitioners}

Most of the Scottish practitioners who participated in the study agreed that male and female practitioners share the same workforce responsibilities and bring their wide ranges of strengths and personalities as individuals. They emphasized the significance of teamwork in the workforce and stated that each individual practitioner could learn from each other and support each other, indicating their non-binary gender subjectivities as shaped by a discourse of individuality in Scotland. For example, Amy and John, working in the same classroom, discussed how they believed that each individual practitioner can be different regardless of their gender, and how working together as different individuals might inspire the children:

I think we've all learnt from each other. [...] And there is no any differentiation with, you have to do that because you are a man and I have to do this because I am woman. $[\ldots]$

(Amy, Female, Edinburgh)

We all do everything $[\ldots]$ like lifting heavy things $[\ldots]$ [T]his is kind of showing the children this is the way you deal with that, $[\ldots]$ ask one of your friends to help you and you can do this together. $[\ldots]$ 
By contrast, the Chinese practitioners in Hong Kong and Tianjin largely agreed that men and women would be undertaking different roles of some kind both within and beyond their teaching and caring for children. Some of the distinctions mentioned most frequently/commonly by almost all female and male practitioners, include that men would usually teach subjects/areas like science and physical sports whereas women are better at subjects like arts and dancing, that men are expected to take responsibility for manual labour and help women with technologies, and that men are rougher and women are more meticulous. To illustrate, $\mathrm{Mr} \mathrm{Hu}$ from Tianjin said that: "I would feel embarrassed if I do not do labour work, being a man." Those gendered role responsibilities as believed by Chinese participant practitioners conform with traditional gender stereotypes about men and women in Chinese cultures and indicate internal gender stratifications within Chinese EYEC workforce. Gender binary thinking hereby suggests its strong influence on shaping Chinese participants' gender subjectivities and their corresponding practices (see Xu [2018]).

\section{Beyond gender-binary roles in China}

Occasionally, however, some Chinese practitioners would challenge established gender stereotypes that define fixed roles of men and women. For instance, Mrs Woo reflected that she was taking on a father's role of discipline in the classroom, despite agreeing (with many other participants) that kindergarten is like a family with a 'mother' and a 'father'. As she put it:

I am stricter and more disciplinary, and Mr Cheung is looser. It's just like how children interact with their parents at home - one will be strict and one will be loose. Usually it's the father who is strict. So in our case, it's nothing to do with gender, but it's more 
down to experience. If he lacks experiences in disciplining, he might overdo it. [...]

That's why I become the one who is strict.

(Mrs Woo, Female, Hong Kong)

Whilst Mrs Woo believed that her adoption of a disciplinary role was unrelated to gender, it is clear from her statements that she (and her male colleague) is complexly challenging as well as accommodating normative discourses. Indeed, Mrs Woo's case was not uncommon in Chinese kindergartens. With most male practitioners being less experienced, Hong Kong and Tianjin kindergartens normally would allocate a more experienced female practitioner to work with a less experienced male practitioner. It was observed that, in most of these cases, the female practitioners were often the ones who disciplined the children more (Xu 2018). As such, experience intersects with gender to impact on the roles of male and female practitioners in Chinese kindergartens.

\section{Different interpretations of male role models in Scotland and China}

Whilst the perceived roles of male and female practitioners are shaped by different cultural discourses of individuality and gender binary in Scotland and China, both contexts are found in this study to be influenced by the strong discourse of the "male role model' (Brownhill 2015) in the subjective constructions of male practitioners' roles in EYEC. Nevertheless, the interpretations of what a male role model would mean to those male practitioners might vary. In Edinburgh, male early years practitioners working in early years centres perceive themselves/are perceived by others as male role models who show children that men could be caring, safe, and positive, challenging gender stereotypes. As many children in those centres might have negative experiences with a man (usually their fathers) at home, or are brought up with single mothers, it is regarded as important for them to have contacts with a positive 'male role model'. Kyle 
provided a detailed explanation on being a positive male role model:

I try to be a positive male role model for the children, I have to show them that they can find me, be confident, feel safe around me because some of these children maybe come from a violent background if there has been a male present. [...] So it's nice for the children to grow up with another male role model, realizing that not everybody is the same. [...] It will benefit them when they grow up, rather than having a male as a negative experience. I want to be a positive experience for the child, respect male and female.

(Kyle, Male, Edinburgh)

Kyle and many other male colleagues in Scotland are trying to challenge some children's experiences with men being tough and violent, and to present non-traditional and caring male figures. His female colleague, Alice agreed on this but further pointed out that being a positive role model is expected of every good practitioner and has little to do with gender. Gavin from another setting added that a role model is there to teach children the right values and is not linked to one's outlook. Ann and Gavin's statements go beyond the binary gender distinctions implied in the 'male role model' discourse and emphasize characteristics that all practitioners are expected to possess, whether male or female.

The interpretations of male role model by some of the Chinese participants in this research, however, were strongly linked to expectations of male practitioners teaching boys about being men in China. Male practitioners believed that their presence in the kindergartens was to make boys aware of their distinctions from girls. Their gender subjectivities in this regard are situated within the discourse of gender socialisation that suggests there are 'masculine' behaviours and characteristics that 
children can learn from, so that boys are masculinized into 'appropriate' male figures expected by the society. Mr Tang, a 'care' practitioner from Tianjin, offered a representative quote that matches with most Chinese male practitioners' understanding of being a male role model:

The way a male teacher behaves in the kindergarten will provide children with masculine influences. I think this is the most important thing to have men working in kindergartens. Because it [the kindergarten] has always been a predominantly female environment, children [boys] are gradually becoming feminised.

(Mr Tang, Male, Tianjin)

Mr Tang also put forward how this gendered discourse of male role model in Chinese society should shape (in his views) male practitioners' performance in kindergartens:

[Researcher: Do you think all male teachers possess those male characteristics?]

Mr Tang: I think I have them in myself, and a male kindergarten teacher has to show those characteristics to children. If you don't have those male characteristics, you will need to purposefully perform in such ways, to develop those characteristics among children.

(Mr Tang, Male, Tianjin)

Being aware that not all men possess expected 'male' characteristics, Mr Tang pointed to the possibilities/necessities of men 'doing' gender in adherence to 'compulsory heterosexuality' (Rich 1980; Butler 1990) in Chinese society. There is no sign however, that Chinese male practitioners would challenge and 'undo' those gendered expectations. 


\section{Gendered practices and pedagogies?}

Having explored how understanding of their roles in EYEC by participant practitioners may (not) be shaped by gender-binary thinking, this section moves on to examine whether Scottish and Chinese practitioners perceive any gender differences in terms of how they approach their shared responsibilities in the EYEC workforce.

\section{Sameness and differences in Scotland}

Scottish participants in this study indicated both sameness and differences with regards to their styles and approaches in their jobs. There seems to be a discourse around everyone (or at least the genders) being 'similar' and at the same time a discourse of everyone being 'different' that paradoxically shaped Scottish participants' gender and/or professional subjectivities. Some female practitioners thought that their practices were similar to their male colleagues because, for example, "[they] manage children in a similar way', 'have same expectations from children', and 'know that children come first before paper work'. The majority of other female and male practitioners emphasized that every individual practitioner has his/her different styles, and it is through communication, support, and teamwork that all those differences are brought together in the workforce. Their subjectivities, again, go beyond gender binaries and reflect a discourse of appreciating individuality and diversity in Scotland.

Nevertheless, some Scottish participants also suggested their uncertainties about essentialist gender differences between men and women, as reflected in their day-to-day practices. For example, Philip was unsure about whether his more disciplinary style is due to his gender or personality, as he also found another female colleague in his centre who has similar style. Kyle noticed that his approach to comforting children is different from his female colleagues. As he explained: 
I've got an expectation that if a child is upset, I would comfort the child and reassure them. Then I would have an expectancy for them $[\ldots]$ to get over the upset more quickly. Maybe sometimes from a female perspective, they tend to take longer, maybe cuddle and attach, walk around with the child in their hand, talking to them, reassure them [...] But I believe sometimes the longer it takes, the harder it gets for the child to separate again. I think that's what we do differently. And I see that quite regular.

(Kyle, Male, Edinburgh)

Carl also believed that women are generally more affectionate and cuddle children more often than men. He even provided a strong statement that reveals binary thinking of gender:

I think men and women are sort of designed to be compatible [...]. [I]n general men are always designed to be opposite women, there is always attractions between men and women in general, which also reflect on people working as well $[\ldots]$.

(Carl, Male, Edinburgh)

It is interesting to see that, on the one hand, Carl regarded himself as an affectionate man and attributed his 'female' characteristics to the 'female influences' he had from his mother and sisters; on the other hand, Carl held strong opinions of gender binary and agreed with the compensational roles that men and women would bring into a workforce respectively. Such paradoxes also existed in Jackie's gender subjectivities, as she deemed that there are differences between men and women, but also pointed out that men are not all the same. Carl's and Jackie's paradoxical constructions of gender, together with other Scottish practitioners' uncertainties about gender differences between men and women, suggest that gender is more complicated than being essentialist characteristics attached to men and women separately, and is socially 
accumulated through experiences and interactions with individuals' wider surroundings. Those paradoxical constructions, however, also reveal the powerful influence of gender binary thinking that still exists in Scottish context.

\section{Individuality and 'performing' gender in Hong Kong}

Like the Scottish practitioners, most of the Hong Kong practitioners also thought that the different styles of working and interacting with children among colleagues was attributable to personalities, knowledge and skills, and most importantly, experiences. Even if men were generally deemed to be less meticulous and less sensitive, and therefore unable to fully address children's various needs (usually caring needs), male and female practitioners in Hong Kong were optimistic that the experiences that male practitioners gained through practices would help reduce this perceived weakness. Gender seemed to be one of the many factors in a matrix that mutually influence on how individual practitioners conduct their work in those Hong Kongese practitioners' eyes, reflecting the same discourse of 'individuality' as in Scotland. And in most cases, gender differences were reported by them to be overridden by individuals' professional experiences working in EYEC.

Two particular views stand out among Hong Kongese practitioners' perceptions of gender differences and offered some inspirational insights into the gender discourses in Hong Kong. Mr Chin regarded his styles and approaches as no different from other female colleagues, because he was intentionally modelling from those more experienced female practitioners in his first year of employment. Assuming that it might be different if he was modelling from a more experienced male practitioner, $\mathrm{Mr}$ Chin on the one hand still held essentialist views of gender; on the other hand, he suggested that he is able to perform in ways that he regarded as incompatible with his gender, in order to 
meet the specific needs of his work and adapt to the predominantly female working environment:

To work with children, a lot of times I have to speak in soft voices and treat children gently. I felt really uncomfortable about this at the start, as you know, men are rough and speak loudly. But I have to be soft because otherwise children will not listen to you. Also, since the whole kindergarten speak in such a way, it might make me look abnormal if I speak roughly and loudly, and perform manly.

(Mr Chin, Male, Hong Kong)

Mr Chin's strategy of 'performing the opposite gender' was also adopted by Mr Chiu, who said that:

I can play a very 'feminine' character in the classroom if needed under certain scenarios, I don't mind. [...] I am a teacher after all, and I need to do as much as I can to cater for my teaching activities. I can't say that I won't do it because it's embarrassing.

(Mr Chiu, Male, Hong Kong)

Mr Chiu's statement does not challenge the gender opposites of being men and women either. It was also implied in his words that performing in 'feminine' ways is embarrassing for a man, and he is therefore sacrificing for his job. Both Mr Chin's and Mr Chiu's interpretations of 'gender performativity' seem to go against Butler's (1990 \& 2004) descriptions of 'doing' gender. Gender is not somethings one 'has' but is something that is constructed through performing it in interaction. Although Mr Chin and Mr Chiu 'think' that they are 'performing' gender, there is an element of them saying they 'know' they are putting on a performance of femininity here that is different from their 'real' gender. Whereas Butler (1990 \& 2004) would say even this 'real' 
gender identity is not 'real'. Further, Mr Chiu's indicated embarrassment might be understood through the hierarchies between (heterosexual) masculinity and femininity, as embedded in the form of 'heterosexual matrix' (Butler 1990).

\section{Essentialist gender differences in Mainland China}

Whilst the Scottish practitioners strongly appreciated each individuals' perceived personal traits and experiences and were sometimes critical of binary gender differences; and the Hong Kongese practitioners prioritized their professional experiences over gender in their work, practitioners from Tianjin overwhelmingly perceived gender in terms of the discourse of essentialist gender differences between men and women and described how such differences result in male and female practitioners' distinctive working styles in EYEC. For example, male practitioners were reported to be engaging more in play activities with children, initiating more big movements and risk-taking activities, and adopting a more boisterous and rougher approach in their teaching and interactions with children. By contrast, female practitioners were assumed to be more meticulous and better attending to details. Male practitioners are 'smooth' and open-minded in their communications with children, whereas female practitioners are more affectionate and softer. The consistencies of those practitioners' interpretations on gender differences between men and women are significant and match with what has been discussed about men's perceived 'unique' contributions to EYEC among Chinese academic literature (Zhao 2016). A list of prevailingly perceived men's and women's gender characteristics in Chinese cultures that emerged from this research is further given below (Table 2 near here).

Those gendered characteristics suggest perpetuating discourses of essentialist and binary gender thinking in which Mainland Chinese practitioners construct their gender 
subjectivities.

No practitioners in Tianjin challenged those gender stereotypes as listed above. Moreover, they also depicted on how their gendered subjectivities shaped their different treatments towards boys and girls in the kindergartens. As Miss Tai reflected:

Maybe because I think girls are more vulnerable, I will pay particular attention to the way I speak to girls. Boys are more outgoing in their characteristics, so I wouldn't care that much.

(Miss Tai, Female, Tianjin)

$\mathrm{Mr} \mathrm{Hu}$ further expanded on this difference and explained how his different treatments to girls and boys are related to the wider gender structure in China:

I would treat boys and girls differently. For girls, I think they are more sensitive, and have stronger self-esteem. [Therefore, I will be careful in the way I speak to them.] But I wish girls to be less strong and more delicate, girls should have girls' traits. [...] Girls will depend on men in the future, so it will not do good to her if she is too strong. [...] And I think I should influence girls in this regard. [...]

For boys, if they make any mistakes, I will not let them go and will definitely blame them hard. There are many suicides among boys now in primary or secondary schools, after their teachers censured them. I would rather give them hard time now, to make them stronger and more resilient. Men suffered more pressures in our society, and I want my boys to be strong enough to cope with those pressures.

(Mr Hu, Male, Tianjin)

Drawing on this hierarchical gender structure in Chinese cultures, $\mathrm{Mr} \mathrm{Hu}$ 's statement points to the issue of how dominant gender discourses including hegemonic masculinity 
(such as that women need to be dependent on men and that men need to be strong) are discursively produced and reiterated from as early as in kindergartens. With the majority of practitioners, male and female, holding strongly gendered subjectivities and performing their jobs in compliance with traditional gender structures, gender transformation (Warin 2019) is not likely to take place in Chinese kindergartens.

\section{Discussion}

By exploring practitioners' gender subjectivities cross-culturally, this study suggests that men could both reproduce traditional gender structures and challenge them, and also that the same is true of women practitioners. To what extent practitioners reproduce or challenge traditional gender structures is strongly influenced by the wider social/gender discourses that situate them. For example, many male and female practitioners in Edinburgh tended to downplay the impact of gender on fulfilling their roles, frequently referring to the discourse of individuality and emphasizing individual personalities and experiences. Drawing on the discourses of 'male role models', some Scottish men practitioners regarded themselves as positive male role models for children, constructing their gender subjectivities as caring and respectful men that are different from expecting male role models to socialize boys with essentialist masculinity - which male practitioners in China strongly draw upon in this study. Many Chinese men and women practitioners were also inclined to emphasize stereotypical gender differences that are shaped by dominant gender discourses of essentialist/biological differences between men and women in China, when describing their contributions to EYEC - especially men practitioners, who frequently mentioned their presence in EYEC as complementary to women in terms of providing boys with male figures to emulate and adding 'male pedagogies' (such as risky, physical play, and so on) to EYEC. 
The cultural variations that differently shape male and female practitioners' gender subjectivities in this study, together with the differences and discursiveness of how individual practitioners relating themselves to dominant gender discourses as evidenced in both many studies (Brody 2014; Brownhill 2014) and in this research (see $\mathrm{Xu}$ [2018]), challenge gender essentialism and suggest gender subjectivities to be diverse within each gender. This paper therefore argues that the widely-endorsed agenda to promote gender diversity in EYEC (Rohrmann and Emilsen 2015; Warin 2019) should go beyond merely including men in the sector. Policies in Scotland, China and elsewhere to increase the number of men working in EYEC (Xu 2018) are to be welcomed, but only as long as they are not underpinned by gender binary and essentialist theories that expect men and women to contribute differently to EYEC. Promoting gender diversity in EYEC would need practitioners to reflect on their own gendered subjectivities that instruct their pedagogies and practices in working with young children. As such, many scholars like Burn \& Pratt-Adams (2015) and Warin \& Adriany (2017) have advocated for gender-sensitive teacher training in EYEC. This paper would further propose a cross-cultural approach to gender-sensitive teacher training in EYEC, transparentising the masked power of cultural discourses (Foucault 1980) and empowering practitioners to challenge them. Cross-cultural reflexivity in EYEC pedagogy and practices offers potential critical opportunities for local practices to be considered and 'judged' in cross-cultural and comparative contexts, meanwhile taking into account both local and international policies and discourses. As gender binary and gender hegemony are still found in this research as pervasive in shaping Scottish and Chinese (including Mainland China and Hong Kong) practitioners' gender subjectivities (although to various extent), challenging hegemonic gender discourses globally would benefit from cross-cultural collaborations and joint efforts. 


\section{Declaration of interest statement:}

The author declares that there is no conflict of interest.

\section{References:}

Blaise, M. 2005. Playing it straight: uncovering gender discourses in the early childhood classroom. New York: Routledge.

Braun, V., and V. Clarke. 2006. "Using thematic analysis in psychology." Qualitative Research in Psychology, 3(2), 77-101. doi: 10.1191/1478088706qp063oa

Brody, D. 2014. Men who teach young children: an international perspective. London: IOE Press.

Brownhill, S. 2014. “'Build me a male role model!' A critical exploration of the perceived qualities/characteristics of men in the early years (0-8) in England." Gender and Education, 26(3), 246-261. doi:10.1080/09540253.2014.901723

Brownhill, S. 2015. "The 'brave' man in the early years (0-8): defining the 'role model'." European Early Childhood Education Research Journal, 23(3), 370379. doi:10.1080/1350293X.2015.1043811

Burn, E., and S. Pratt-Adams. 2015. Men teaching children 3-11: dismantling gender barriers. London: Bloomsbury.

Butler, J. 1990. Gender trouble: feminism and the subversion of identity. London: Routledge.

Butler, J. 2004. Undoing gender. Abington: Routledge.

Census and Statistics Department. 2018. Hong Kong Annual Digest of Statistics: Section 12 Education. HK SAR. Accessed August 10, 2019. https://www.statistics.gov.hk/pub/B10101232018AN18B0100.pdf

Fereday, J., and E. Muir-Cochrane. 2006. "Demonstrating rigor using thematic analysis: a hybrid approach of inductive and deductive coding and theme development." 
International Journal of Qualitative Methods, 5(1), Article xx. Accessed February

http://www.ualberta.ca/ iiqm/backissues/5_1/pdf/fereday.pdf

Foucault, M. 1980. Power/Knowledge: selected interviews and other writings 19721977. New York: Pantheon.

Foucault, M. 1982. "The subject and power." In Michel Foucault: beyond structuralism and hermeneutics, edited by H. Dreyfus and P. Rabinow, 208-226. Chicago: University of Chicago Press.

Hauari, H., and K. Hollingworth. 2009. Understanding fathering: masculinity, diversity and change. $\quad$ Accessed $\quad$ February 24, https://www.jrf.org.uk/report/understanding-fathering-masculinity-diversityand-change

Ho, D., and H. Lam. 2014. "A study of male participation in early childhood education: perspectives of school stakeholders." International Journal of Educational Management, 28(5), 498-509. doi:10.1108/IJEM-02-2013-0024

Johansson, T. 2011. "The construction of the new father: how middle-class men become present fathers." International Review of Modern Sociology, 37(1), 111-126. Accessed February 24, 2019. http://www.jstor.org/stable/41421402

Laere, K. V., M. Vandenbroeck, G. Roets, and J. Peeters. 2014. "Challenging the feminisation of the workforce: rethinking the mind-body dualism in Early Childhood Education and Care." Gender and Education, 26(3), 232-245. doi:10.1080/09540253.2014.901721

Livingston, G. 2014. Growing number of dads home with the kids: biggest increase among those caring for family. Washington, D.C.: Pew Research Center's Social and Demographic Trends project, June. Accessed February 24, 2019. 
http://www.pewsocialtrends.org/2014/06/05/growing-number-of-dads-homewith-the-kids/

Ministry of Education of the People's Republic of China. 2018. Number of female educational personnel and full-time teachers of schools by type and level. $\begin{array}{llll}\text { Accessed } & \text { August } & 2019 .\end{array}$ http://www.moe.gov.cn/s78/A03/moe_560/jytjsj_2017/qg/201808/t20180808_3 $\underline{44693 . h t m l}$

O'Connor, D. 2001. "Journeying the quagmire: exploring the discourses that shape the qualitative research process.” Affilia: Journal of Women and Social Work, 16(2), 138-158. doi:10.1177/08861090122094190

OECD. 2018. Education at a glance 2018: OECD indicators. Paris: OECD Publishing. Accessed February 24, 2019. https://doi.org/10.1787/19991487

Osgood, J. 2005. "Who cares? The classed nature of childcare." Gender and Education, 17(3), 289-303. doi:10.1080/09540250500145098

Peeters, J., T. Rohrmann, and K. Emilsen. 2015. "Gender balance in ECEC: why is there so little progress?" European Early Childhood Education Research Journal, 23(3), 302-314. doi:10.1080/1350293X.2015.1043805

Rich, A. 1980. "Compulsory heterosexuality and lesbian existence." Women: Sex and Sexuality, 5(4), 631-660. Accessed February 24, 2019. http://www.jstor.org/stable/3173834

Roberts-Holmes, G. P. 2009. “"People are suspicious of us': a critical examination of father primary carers and English early childhood services." Early Years, 29(3), 281-291. doi:10.1080/09575140902989870 
Rohrmann, T. and D. Brody. 2015. "Questioning methodologies in research on men in ECEC." European Early Childhood Education Research Journal, 23(3), 405416. doi:10.1080/1350293X.2015.1043814

Rohrmann, T., and K. Emilsen. 2015. "Editorial.” European Early Childhood Education Research Journal, 23(3), 295-301. doi:10.1080/1350293X.2015.1043804

Scottish Social Services Council. 2018. Scottish social service sector: report on 2017 workforce data: an official statistics publication for Scotland. Dundee: Scottish Social Services Council. Accessed August 10, 2019. https://data.sssc.uk.com/images/WDR/WDR2017.pdf

Sumsion, J. 2005. "Male teachers in early childhood education: issues and case study." Early Childhood Research Quarterly, 20(1), 109-123. doi:10.1016/j.ecresq.2005.01.001

Tennhoff, W., J. C. Nentwich, and F. Vogt. 2015. "Doing gender and professionalism: exploring the intersectionalities of gender and professionalization in early childhood education." European Early Childhood Education Research Journal, 23(3), 340-350. doi:10.1080/1350293X.2015.1043808

Tobin, J., Y. Hsueh, and M. Karasawa. 2009. "Preschool in three cultures revisited: China, Japan, and the United States." Chicago: The University of Chicago Press.

Twinn, S. 1997. "An exploratory study examining the influence of translation on the validity and reliability of qualitative data in nursing research." Journal of Advanced Nursing, 26(2), 418-423. $\quad \underline{\text { doi:10.1046/j.1365- }}$ $\underline{2648.1997 .1997026418 . x}$

Warin, J. 2014. "The status of care: linking gender and 'educare'.” Journal of Gender Studies, 23(1), 93-106. doi:10.1080/09589236.2012.754346 
Warin, J. 2019. “Conceptualising the value of male practitioners in early childhood education and care: gender balance or gender flexibility." Gender and Education, 31(3), 293-308. doi:10.1080/09540253.2017.1380172

Warin, J., and V. Adriany. 2017. "Gender flexible pedagogy in early childhood education." Journal of Gender Studies, 26(4), 375-386. doi:10.1080/09589236.2015.1105738

$\mathrm{Xu}, \mathrm{Y} .2018$. "A cross-cultural analysis of gender and practitioner-child interactions in Early Childhood Education and Care (ECEC) settings in Scotland, Hong Kong, and Mainland China.” PhD diss., University of Glasgow.

Xu, Y., and M. Waniganayake. 2018. "An exploratory study of gender and male teachers in early childhood education and care centres in China." Compare: A Journal of Comparative and International Education, 48(4), 518-534. doi:10.1080/03057925.2017.1318355

Yang, Y., and D. E. McNair. (2019). "Male teachers in Shanghai public kindergartens: a phenomenological study." Gender and Education, 31(2), 274-291. doi:10.1080/09540253.2017.1332339

Zhao, Y. 2016. "Literature review on the study of male preschool teacher in recent 10 Years - on the Basis of CNKI (2006-2016).” [In Chinese.] Journal of Shaanxi Xueqian Normal University, 32(10), 146-149. 
Table 1 Participants' demographic information

\begin{tabular}{|c|c|c|c|c|c|c|c|}
\hline Pseudonym & Gender & Age & $\begin{array}{c}\text { Working } \\
\text { experience } \\
\text { (years) }\end{array}$ & Qualifications & Position & Setting & City \\
\hline Kyle & $\mathrm{M}$ & 46 & 9 & \multirow{4}{*}{$\mathrm{HNC}^{1}$} & \multirow{4}{*}{$\begin{array}{l}\text { Early } \\
\text { Years } \\
\text { Officer }\end{array}$} & \multirow{4}{*}{$\begin{array}{l}\text { Early } \\
\text { Years } \\
\text { Centres }\end{array}$} & \multirow{14}{*}{ Edinburgh } \\
\hline Alice & $\mathrm{F}$ & $<50$ & 25 & & & & \\
\hline Raymond & M & 58 & 12 & & & & \\
\hline Jackie & $\mathrm{F}$ & 45 & 27 & & & & \\
\hline Philip & $\mathrm{M}$ & 33 & \multirow{2}{*}{1.5} & BSc Physics & \multirow{2}{*}{$\begin{array}{c}\text { Nursery } \\
\text { Practitioners }\end{array}$} & \multirow{2}{*}{$\begin{array}{l}\text { Private } \\
\text { Nursery }\end{array}$} & \\
\hline Connie & $\mathrm{F}$ & 28 & & SVQ Level 3 & & & \\
\hline Sean & $\mathrm{M}$ & 29 & 3 & BA; HNC & \multirow{2}{*}{$\begin{array}{l}\text { Early Years } \\
\text { Practitioner }\end{array}$} & \multirow{4}{*}{$\begin{array}{c}\text { Early } \\
\text { Years } \\
\text { Centres }\end{array}$} & \\
\hline Jenny & $\mathrm{F}$ & 28 & 7 & BSc; HNC & & & \\
\hline Carl & $\mathrm{M}$ & 48 & 13 & $\mathrm{HNC}$ & \multirow{2}{*}{$\begin{array}{c}\text { Early Years } \\
\text { Officer }\end{array}$} & & \\
\hline Laura & $\mathrm{F}$ & 28 & 5 & BA; HNC & & & \\
\hline Gavin & M & 38 & 10 & SVQ Level 3 & Deputy Manager & \multirow{2}{*}{$\begin{array}{l}\text { Private } \\
\text { Nursery }\end{array}$} & \\
\hline Heather & $\mathrm{F}$ & 25 & 1 & \multirow{3}{*}{$\mathrm{HNC}$} & \multirow{2}{*}{ Practitioner } & & \\
\hline Mr John Hill & $\mathrm{M}$ & 45 & 4 & & & \multirow{2}{*}{$\begin{array}{c}\begin{array}{c}\text { Primary } \\
\text { School } \\
\text { Nursery Class }\end{array} \\
\end{array}$} & \\
\hline Mrs Amy Smith & $\mathrm{F}$ & 46 & 23 & & Early Years Officer & & \\
\hline Mr Cheung & $\mathrm{M}$ & $>20$ & 2 & $\mathrm{HD}^{2}$ & \multirow{10}{*}{$\begin{array}{c}\text { Class } \\
\text { Teachers }\end{array}$} & \multirow{10}{*}{$\begin{array}{l}\text { Local } \\
\text { Kindergarten } \\
3\end{array}$} & \multirow{10}{*}{ Hong Kong } \\
\hline Mrs Woo & $\mathrm{F}$ & $>30$ & 20 & N/A & & & \\
\hline Mr Ngai & $\mathrm{M}$ & 21 & $<1$ & HD & & & \\
\hline Ms Wah & $\mathrm{F}$ & 44 & 18 & $\mathrm{BEd}^{4}$ & & & \\
\hline Mr Fok & $\mathrm{M}$ & \multirow{2}{*}{$>30$} & 8 & HD; BEd & & & \\
\hline Ms Choi & $\mathrm{F}$ & & 18 & BEd & & & \\
\hline Mr Chin & $\mathrm{M}$ & 26 & 4 & $\mathrm{HD}$; BEd & & & \\
\hline Ms Yau & $\mathrm{F}$ & $>30$ & 13 & BEd & & & \\
\hline Mr Chiu & M & 24 & 2 & $\mathrm{HD}$; BEd & & & \\
\hline Miss Tso & $\mathrm{F}$ & 33 & $10-11$ & HD & & & \\
\hline Mr Bai & $\mathrm{M}$ & 25 & 3 & $\mathrm{BEd}$ & Assistant Teacher & \multirow{4}{*}{$\begin{array}{c}\text { Public } \\
\text { Kindergarten } \\
5\end{array}$} & \multirow{10}{*}{ Tianjin } \\
\hline Ms Bao & $\mathrm{F}$ & $>30$ & 4 & MA in Sports & Lead Teacher & & \\
\hline Mr Han & $\mathrm{M}$ & 23 & 3 & $\mathrm{BEd}$ & Assistant Teacher & & \\
\hline Mrs Hua & $\mathrm{F}$ & 47 & 26 & BEd & Lead Teacher & & \\
\hline Mr Tang & $\mathrm{M}$ & 20 & $2-3$ & HD & "Care' Teachere' & \multirow{2}{*}{$\begin{array}{c}\text { Private } \\
\text { Kindergarten }\end{array}$} & \\
\hline Miss Tai & $\mathrm{F}$ & \multirow{2}{*}{27} & 4 & BEd & \multirow{2}{*}{ Lead Teacher } & & \\
\hline $\mathrm{Mr} \mathrm{Hu}$ & $\mathrm{M}$ & & 2 & \multirow{2}{*}{$\begin{array}{c}\text { BSc in } \\
\text { Management }\end{array}$} & & \multirow{4}{*}{$\begin{array}{c}\text { Public } \\
\text { Kindergarten }\end{array}$} & \\
\hline Miss He & $\mathrm{F}$ & 26 & 1.5 & & \multirow{2}{*}{ Assistant Teacher } & & \\
\hline Mr Niu & $\mathrm{M}$ & 20 & 3 & \multirow{2}{*}{$\mathrm{HD}$} & & & \\
\hline Mrs Niew & $\mathrm{F}$ & $<50$ & 28 & & Lead Teacher & & \\
\hline
\end{tabular}

${ }^{1}$ Higher National Certificate (HNC) in Early Education and Childcare

${ }^{2}$ High Diploma (HD) in Early Childhood Education

3 The local kindergartens account for about $85.5 \%$ of all kindergartens in Hong Kong (Census and Statistics Department 2018).

${ }^{4}$ Bachelor in Early Childhood Education

${ }^{5}$ Most Chinese male kindergarten teachers are inclined to work in public kindergartens as a result of better salaries and welfare benefits (Xu and Waniganayake 2018).

${ }^{6}$ A 'care' practitioner in a Mainland Chinese kindergarten is someone whose main responsibilities include housekeeping, cleaning, serving meals, and so on - things that are regarded as more 'caring' than 'educational'. 
Table 2 Perceived men's and women's gender characteristics in China

\begin{tabular}{|c|c|}
\multicolumn{1}{c|}{ Men } & Women \\
Playful & Mothering \\
Risky & Caring \\
Boisterous & Quiet \\
Rough & Meticulous \\
Smooth & Patient \\
More verbal encouragement & More cuddling \& kisses \\
Rational & Emotional \\
Better at subjects such as science and & Better at subjects such as arts and dancing \\
technologies &
\end{tabular}

